\title{
Neonatology, paediatrics and paediatric virology on a British island: An interview with neonatologist Dr Prakash Thiagarajan (Isle of Man)
}

\author{
IOANNIS N. MAMMAS and DEMETRIOS A. SPANDIDOS \\ Department of Clinical Virology, School of Medicine, University of Crete, Heraklion 71003, Greece
}

Received June 22, 2018; Accepted July 23, 2018

DOI: $10.3892 /$ etm.2018.6544

\begin{abstract}
Dr Prakash Thiagarajan, consultant neonatologist and clinical director at Women's and Children's Division at Noble's Hospital on the Isle of Man, is one of the most talented neonatologists in the UK with a great experience in newer modes of infant ventilation and the application of technology in neonatal medicine and paediatrics. Under his leadership, the new neonatal intensive care unit (NICU) at Noble's Hospital is a state-of-the-art neonatal unit offering the very highest standards of care for critically ill babies on the island. Dr Thiagarajan highlights the re-emergence of continuous positive airway pressure (CPAP) as a key mode of ventilatory support for preterm infants and describes the current practice relating to the transport of the critically ill newborn and paediatric population. He reports the main milestones of the Isle of Man preparedness plan for influenza during the 2009 A/H1N1 influenza pandemic and he emphasises the role of immunisations and high level infection control measures in preventing future outbreaks of viral illnesses in children. He accepts that paediatric virology is an extremely important, yet underserved area of paediatrics and as with any clinical specialty, it is very important for effective two-way communications between frontline clinicians and academic researchers. He sums up suggesting the formation of the 'European Society for Paediatric Virology' in order to propagate knowledge and training in paediatric virology to health professionals, set standards in training, promote research and development and also raise public awareness. In the context of the "4th Workshop on Paediatric Virology', which will be held in Athens, Greece, on September 22nd, 2018, Dr Thiagarajan's plenary lecture will focus on antiviral drugs in the clinical management of children with influenza.
\end{abstract}

Correspondence to: Professor Demetrios A. Spandidos, Department of Clinical Virology, School of Medicine, University of Crete, Heraklion 71003, Greece

E-mail: spandidos@spandidos.gr

Key words: neonatology, paediatrics, neonatal transfers, 2009 A H1N1 influenza pandemic, paediatric virology, workshop, Isle of Man, Dr Prakash Thiagarajan

\section{Contents}

1. Introduction

2. Questions and Answers

\section{Introduction}

Dr Prakash Thiagarajan (Fig. 1), clinical director of the Women's and Children's Health and lead consultant neonatologist at Noble's Hospital in the Isle of Man, is considered as one of the most talented neonatologists in the UK. Born in May 18th, 1967, he studied medicine at the Christian Medical College in Vellore (India) and he was trained in paediatrics in the UK in Birmingham Heartlands and Solihull Hospitals in Birmingham, West Midlands (England), Singleton Hospital in Swansea (Wales) and King's College Hospital in London, where he worked under the supervision of Professor Anne Greenough, Professor of Neonatology and Clinical Respiratory Physiology at the King's College London (London, UK). In 1997, he moved to Australia, where he completed a two-year neonatal fellowship in neonatology at the King Edward Memorial Hospital in Subiaco, Perth (Western Australia). In 1999, he moved to New Zealand, where he was appointed as a consultant paediatrician and neonatologist in the Dunedin Hospital and senior lecturer in Paediatrics at the University of Otago in Dunedin (New Zealand). From 2003 to 2005, he continued in Jersey General Hospital in Jersey (Channel Islands) as a consultant paediatrician and neonatologist, where he was the lead clinician for neonatology with responsibilities of tutorship for the Royal College of Paediatrics and Child Health ( $\mathrm{RCPCH})$. Since December 2005, he has been working in Douglas at the Isle of Man as a consultant paediatrician and neonatologist with a lead role in neonatology and since 2015, he is the Clinical Director of the Division for Women's and Children's Health at Noble's Hospital. He is a fellow of the Royal College of Physicians of Edinburgh (RCPE) and the RCPCH, where he is a specialist training assessor and member of the Council of Reference (neonatology).

To date, Dr Thiagarajan has played an outstanding role in the provision of state-of-the-art neonatal services in the Isle of Man. In addition to his clinical interests in neonatology (neonatal respiratory physiology, newer modes of infant ventilation, neonatal intensive care transport and the application of 
technology in neonatology), he has exemplary contributed in healthcare quality improvement and patient safety (1-14). He has played a leading role in procuring appropriate equipment for neonatal care including the procurement of a neonatal ultrasound scanner, cardio-respiratory monitors, cold light illuminator, high resolution monitors and high-frequency ventilator. He liaises with the Mersey and Cheshire Neonatal Network regularly and working with the neonatal team he has helped maintain the level two status of the neonatal unit in Douglas. Recently, he initiated and completed in collaboration with the lead neonatal nurse, Paul McCann, and the clinical general manager, Linda Radcliffe, the bid for reconfiguration and rebuild of the local neonatal unit in Douglas; the new unit was opened in 2015 and is currently providing neonatal intensive care to infants born beyond 27 weeks of gestation. Moreover, he has assisted in the tendering process for the provision of air ambulance service to the Isle of Man. Since 1995, he has led several neonatal transport teams on a regular basis in the transport of critically ill newborn infants. He also has experience in the transport of infants by air over large distances.

Dr Thiagarajan has an enthusiastic teaching role in the clinical practice of paediatric and neonatal trainees with both formal educational sessions and informal bedside teaching. $\mathrm{He}$ has participated in teaching the part II MRCP clinical course at King's College Hospital and he has also lectured in its postgraduate neonatal nursing course. His involvement with undergraduate medical student teaching has included bedside clinical teaching sessions, tutorials and systems integration teaching. He has been an examiner for 5 th year end of term Objective Structured Clinical Examinations (OSCE) in paediatrics and the New Zealand Diploma in Child Health (DCH) examinations. In 2007, he was involved in bringing and organising the 2007 Annual Meeting of the British Association of Perinatal Medicine (BAPM) to the Isle of Man. Recently, he has just been elected as 'president-elect' of the Isle of Man Medical Society.

To date, Dr Thiagarajan has helped and supported the Paediatric Virology Study Group (PVSG) since its birth and has been member of its academic advisory board. In 2016, he gave the plenary lecture of the '2nd Workshop on Paediatric Virology' entitled 'Zika virus (ZV) in pregnancy and infancy 'What do the paediatricians need to know?' and he was awarded with the '2016 Paediatric Virology Award in Neonatology' for his outstanding academic, clinical, research and publishing contribution on neonatal medicine $(14,15)$. In the context of the '4th Workshop on Paediatric Virology', his plenary lecture will focus on antiviral drugs in the clinical management of children with influenza. Moreover, he will discuss with the workshop's participants on the Noble's pandemic influenza planning process, including drafting the triage algorithms for children.

\section{Questions and Answers}

Question: Vellore, Birmingham, Swansea, London, Perth in Western Australia, New Zealand, Jersey, Isle of Man. Among all these places, which one was the most significant in your neonatal and paediatric experience?

Answer: Each and every one of the training jobs shaped me as a personandaclinician.Iwasamedical studentinthelabourwardina large teaching hospital (more than 10,000 deliveries per annum) when one of the labouring women I observed was in premature

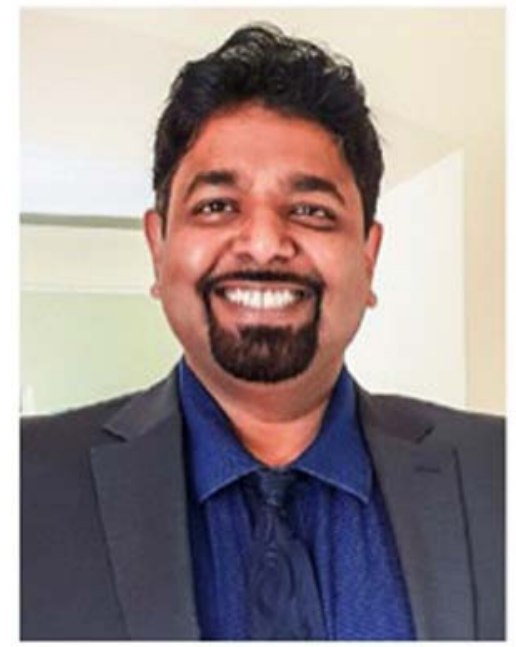

Figure 1. Dr Prakash Thiagarajan, Consultant Neonatologist and Clinical Director at Women's and Children's Division at Noble's Hospital on the Isle of Man and Chair of the '4th Workshop on Paediatric Virology', Athens, Greece.

labour at 25 weeks gestation and delivered a live infant. The infant was merely wrapped in a dry towel and was left to die on a resuscitaire, with no one making any effort to resuscitate him. When I questioned it, I was informed that the infant was 'pre-viable' gestation and therefore was allowed to die. Observing this had the most profound impact on me as a medical student, and that was the day I decided to specialise in neonatology. I also got a very good grounding in clinical medicine and paediatrics by exposure to a huge number of patients. During my internship, we experienced a large outbreak of measles in children, many of whom presented with devastating complications of measles and that got me interested in paediatric infectious diseases.

In Birmingham and Swansea, I had the opportunity to get very good general paediatric training and sound training in general neonatology. I must particularly mention Dr Jean Matthes in Swansea, who encouraged me to specialise in neonatology and taught me a lot. At King's College Hospital in London, I was fortunate to train under some excellent academic neonatologists, such as Professor Anne Greenough and Professor Janet Rennie. Both are excellent neonatologists, researchers and teachers and I learnt how to practice evidence-based neonatology there.

In King Edward Memorial Hospital, Perth, I was fortunate to work for some stalwarts of neonatology, such as (late) Professor Alfred Grauaug, Dr Rolland Kohan, Professor Ronnie Hagan and Dr Noel French. This is the largest neonatal unit in the Southern Hemisphere and covers a vast region of Australia, the whole of Western Australia. I got a lot of hands-on training in practical procedures and airborne transport and retrieval of critically ill neonates. However, for the first month of my fellowship there, I was watched by Professor Grauaug like a hawk! Every single decision of mine was questioned and I was expected to defend my decisions using evidence. Obviously, I was getting concerned by this degree of attention - the other fellows were not getting this degree of scrutiny - and my concerns were heightened when at the end of my first month, I was summoned to Professor's office at 5:30 p.m. on a busy day after we had just admitted and stabilised 24-week triplets. I knocked and entered his office 
with some trepidation. He asked me how I thought my fellowship was going and I replied 'reasonably well'. He thought for a moment and replied, 'you are a bloody good neonatologist in the making!' He then asked if I could hold his on-call bleep for $4 \mathrm{~h}$ that evening as he had to attend his daughter's recital and close scrutiny of my practice ended that day!

Question: You had the chance to work in London with our 'queen of neonatology' Professor Anne Greenough at King's College Hospital in London. What was the most significant lesson that you received from her?

Answer: Anne was one of the best teachers of neonatology that I have been fortunate to train under. Attention to detail and focus on evidence based neonatal practice are two cardinal principles I learnt from her and to this day, they have stood me in good stead.

Question: You are considered as a one of the most talented neonatologists in the UK with a great experience in newer modes of infant ventilation and the application of technology in neonatal medicine. According to you, what are the most significant recent developments of modern neonatology?

Answer: Thank you for your kind words, but I believe I am one of many neonatologists, who do good work every day. It is hard to pinpoint one significant recent development, but if I have to choose one, I would say that it is the re-emergence of continuous positive airway pressure (CPAP) as a key mode of ventilatory support for preterm infants, as it is relatively non-invasive, widely available, cost-effective and if used appropriately, extremely effective, with minimal adverse effects.

Question: Under your leadership, the neonatal intensive care unit (NICU) at Noble's Hospital is a state-of-the-art neonatal unit offering the very highest standards of care for critically ill babies. How challenging is it for you to provide excellent care for neonates and support for their parents and families on the island? In our country, in the Greek island of Rhodes, a similar island in shape and population as Isle of Man, the majority of women deliver their babies in Athens and not on the island.

Answer: As always, the success of our neonatal unit in providing level-two neonatal care is down to team work. We have achieved an effective collaboration between medical professionals, nursing professionals and parents at our hospital and also the collaborative support of our tertiary colleagues and the North West Neonatal Network. We have agreed clear care pathways. For example, the network is happy for us to provide neonatal care for all infants born after 27 weeks of gestation. We also provide intensive care transport and retrieval ourselves. It will absolutely be possible to replicate this at Rhodes. If a group of clinicians at Rhodes get together with some parents and get the support of a large tertiary neonatal unit at Athens, convince those who hold the purse-strings, you should be able to get to the stage of delivering and caring for most of your babies close to their homes and their families! I will be more than happy to collaborate with you and your colleagues to make this a reality.

Question: You were the one, who dreamed about a new NICU at Noble's Hospital and you were actively involved in its construction, which commenced in October 2013. How difficult was your vision to be planned and to become a reality? Answer: We started planning for and lobbying for a new level-two neonatal unit in 2007 and we finally moved into the new building in 2015. As you can see, it was a long and arduous journey, but an entirely worthwhile one. The initial step was to get the clinicians united, charged with this purpose, we then involved the parents of infants, who have needed neonatal care, then convinced the managers and politicians. The hardest part was convincing those who held the purse-strings (treasury). Once we did that, the rest was relatively easy.

Question: Underwater birth has been considered as a safe method of delivery for healthy women with uncomplicated pregnancies. However, in 2008, we reported in the Journal of Maternal-Fetal and Neonatal Medicine 2 cases of water aspiration syndrome at birth (2). Since then, what has changed at your local protocols regarding underwater births?

Answer: The most significant change in the way that underwater labour and delivery is offered to prospective mothers is the availability of detailed information and pre-birth counselling so that they can make an informed choice. It is made very clear that there is a small, but significant rate of complications when infants are delivered under water and therefore, the mothers make a conscious choice to labour and/or deliver under water.

Question: Neonatal and paediatric air transfers by air for advanced or specialty medical care should be undertaken by multidisciplinary transport teams in a manner that is safe for both staff and our little patients. What is your current practice at the Isle of Man relating to transport of the critically ill newborn and paediatric population?

Answer: We have a small, highly skilled neonatal transport team consisting of paediatricians and neonatal nurses. All the team members are trained in neonatal retrieval and transfer. In addition, we are supported by medical physics colleagues and ambulance and flight crews. We maintain detailed data and audit our practice regularly. More recently, we have also started multi-professional simulation training, which we find very helpful.

Question: ZV in pregnancy and infancy. What do paediatricians need to know?

Answer: $\mathrm{ZV}$ is a single-stranded RNA virus, closely related to dengue fever, yellow fever, Japanese encephalitis and WNV infections. Zika is the name of the disease caused by this virus. The primary mode of transmission is via the bite of infected Aedes aegypti and Aedes albopictus mosquitoes. Other modes of infection include maternal/foetal transmission (intrauterine and perinatal), sexual transmission and laboratory exposure. Outbreaks have occurred in 48 countries and territories. All age groups are affected, although adults are more likely to seek medical attention. The clinical illness is usually mild, the incubation period varies from 3 to 14 days and viraemia occurs for up to a week. The majority of the infections are subclinical and the most common clinical features include an acute onset of fever, maculopapular rash, arthralgia and conjunctivitis, although headaches and myalgia have also been reported. ZV during pregnancy is of particularly concern as foetal and peri- 
natal transmission have been reported, causing microcephaly and other severe defects, including eye defects, hearing loss, impaired growth and foetal loss. Definitive diagnosis is based on the detection of ZV ribonucleic acid (RNA) in blood serum or ideally, ethylenediaminetetraacetic acid (EDTA)-treated plasma and other body fluids by polymerase chain reaction (PCR). There is no treatment available for $\mathrm{ZV}$ infections at present and therefore, prevention is the only option by avoiding travel to areas of high incidence of $\mathrm{ZV}$, use of insect repellents and mosquito nets to prevent mosquito bites, and advising avoidance of direct sexual contact with those affected.

Question: Paediatric virology, which combines paediatrics with clinical virology, is a bold, new and rapidly increasing educational challenge. According to your neonatal and paediatric clinical practice, what are the most important advances in the management and prevention of neonatal and paediatric viral infections?

Answer: Immunisations and professionals, who practice high level infection control measures, have had the highest impact in preventing outbreaks of viral illnesses in children. Awareness, early diagnosis and treatment for treatable viral illnesses will lead to the best outcomes of affected children. I think the biggest therapeutic challenges this century will be treating children infected with both newly emerging and re-emerging viral illnesses for which therapeutic options are very limited.

Question: To date, our PVSG has evaluated paediatric virology as a new candidate for paediatric subspecialisation (16). The number of paediatric virologists in each country should be limited with a leading academic, clinical and research role, though. How necessary do you believe that this option is in future medicine?

Answer: The PVSG is an excellent initiative that has brought together various clinical and academic specialists in this area. Paediatric virology is an extremely important, yet underserved area of paediatrics and as with any clinical specialty, it is very important for effective two-way communications between frontline clinicians and academic researchers to continue in order to target research towards clinically relevant outcomes and also to start early implementation of therapies that research outputs. A balance must be struck between concentrating expertise in paediatric virology and ready availability of sound, up-to-date advice for frontline clinicians whilst limiting the total number of paediatric virologists. I would suggest that this group should take the next step and form the 'European Society for Paediatric Virology' in order to propagate knowledge and training in paediatric virology to health professionals, set standards in training, promote research and development and also raise public awareness.

Question: During my time on the Isle of Man in 2008, just one year before the $2009 \mathrm{~A} / \mathrm{H} 1 \mathrm{~N} 1$ influenza pandemic, I had the chance to attend your outstanding teaching on the Isle of Man preparedness plan for influenza. Your lecture was really 'prophetic' regarding the upcoming outbreak one year later! Almost 100 years ago, in October 1918, one third of the population of another Greek island, Skyros, was devastated due to the 'Spanish' influenza (17). What are the main milestones of being prepared against a future influenza outbreak?
Answer: I am saddened to learn that one third of the population of Skyros was killed by influenza in 1918. The 7 key steps for being prepared for an epidemic/pandemic of influenza are: i) Horizon scanning; keeping a close watch for outbreaks elsewhere; ii) stocking/ordering sufficient vaccines to immunise at least half the population; iii) stocking sufficient courses of antivirals to treat approximately one fifth of the population with more than one type of anti-viral in case of resistance developing during the epidemic; iv) stocking sufficient personal protective equipment (PPEs) for staff; v) devising clear clinical pathways for children presenting with a flu-like illness; vi) drawing clear contingency plans for isolating and treating these children including identifying the physical space and ordering sufficient diagnostic kits; and vii) multi-professional simulation training including other agencies such as police, education and social services.

Question: In your lecture at the forthcoming "4th Workshop on Paediatric Virology' on September 22nd, 2018, in Athens, you will focus on the current clinical management of children with influenza. What will be the key messages of your lecture? Answer: Thank you for inviting me to give this lecture in beautiful Athens. My key messages will be to: i) Focus on prevention-immunisation and good infection control measures; ii) train medical and nursing workforce very well in infection control measures and the recognition and early treatment of children with influenza; iii) draft clear plans for diagnosing, treating and isolating children with influenza and include simulation training as part of the preparations; and iv) stock adequate antivirals.

Question: Thank you for your valuable time. We are looking forward to your presence, your chairmanship and your lecture in Athens on September!

\section{References}

1. Waspe J, Lahtinen A and Thiagarajan P: Premedication for non-emergent neonatal intubation: Evolution of UK practice, 1998-2015. Acad J Ped Neonatol 3: 555620, 2017.

2. Mammas IN and Thiagarajan P: Water aspiration syndrome at birth - report of two cases. J Matern Fetal Neonatal Med 22: 365-367, 2009.

3. Mammas I and Thiagarajan P: Neonatal and paediatric air transfers: The Isle of Man experience. Acta Paediatr 97: 1600, 2008.

4. Thiagarajan P: Pandemic Influenza: A teaching module, 2005. www.doctors.net.uk.

5. Highton D, Thiagarajan P and Broadbent RS: The efficacy of trans-cutaneous bilirubinometry: A comparison with serum bilirubin in a New Zealand population. In: Proceedings of the 6th Annual Congress of the Perinatal Society of Australia and New Zealand and the 12th Congress of the Federation of the Asia and Oceania Perinatal Society, 2002.

6. Broadbent RS and Thiagarajan P: Recipient twin limb ischaemia. In: Proceedings of the 28th Meeting of the New Zealand Fetal and Neonatal Physiological Society, 2001.

7. Highton D, Thiagarajan P and Broadbent RS: The efficacy of trans-cutaneous bilirubinometry: A comparison with serum bilirubin in a New Zealand population. Proc Univ Otago Med Sch 157: A8, 2001

8. Thiagarajan $\mathrm{P}$ and Johns K: Audit of temperature of pre-term infants admitted to the neonatal intensive care unit. Swansea Audit Symposium, 1995.

9. Thiagarajan P and Matthes JWA: An Audit of the management of urinary tract infection in children under four years. Swansea Audit Symposium, 1994. 
10. Thiagarajan P and Grauaug A: An Audit into the use of home oxygen therapy for infants with chronic lung disease. Presented in the Grand Rounds of Princess Margaret Hospital, 1998.

11. Broadbent RS, Thiagarajan P and Craw S: Limb ischemia in twin premature neonates: Case reports and literature review. In: Proceedings of the Perinatal Society of Australia and New Zealand 4th Annual Congress, 2000.

12. Thiagarajan P, Grauaug A, Tompkins J and Gurrin L: Extremely preterm infants, broncho-pulmonary dysplasia and home oxygen. In: Proceedings of the Perinatal Society of Australia and New Zealand 3rd Annual Congress, 1999.

13. Mydam J and Thiagarajan P: A nine month old child with retropharyngeal abscess secondary to mastoid abscess presenting as torticollis: A case report. Cases J 2: 6460, 2009.

14. Thiagarajan P: Zika Virus in pregnancy and infancy - What do the paediatricians need to know? Int J Mol Med 38: S64, 2016.

15. Mammas IN, Theodoridou M, Kramvis A, Thiagarajan P, Gardner S, Papaioannou G, Melidou A, Koutsaki M, Kostagianni G, Achtsidis V, et al: Paediatric Virology: A rapidly increasing educational challenge. Exp Ther Med 13: 364-377, 2017.
16. Mammas IN, Greenough A, Theodoridou M and Spandidos DA: Paediatric Virology: A new paediatric subspecialty? A proposal at the Workshop on Paediatric Virology, Athens, October 10, 2015. Exp Ther Med 11: 3-5, 2016.

17. Mammas IN, Theodoridou M and Spandidos DA: The 1918 Spanish flu outbreak that devastated a Greek island underlines past lessons that must never be forgotten. Acta Paediatr: Mar 31, 2018 (Epub ahead of print).

This work is licensed under a Creative Commons Attribution-NonCommercial-NoDerivatives 4.0 International (CC BY-NC-ND 4.0) License. 